\title{
O PRINCÍPIO DA UNIVERSALIZAÇÃO EM RAWLS E HABERMAS: UMA AVALIAÇÃO CRÍTICA
}

Luiz Antonio de Oliveira Lima

THE PRINCIPLE OF THE UNIVERSALIZATION IN RAWIS AND HABERMAS: A CRITICAL VIEW

\section{RESUMO}

O OBJETIVO DESTE ARTIGO É APRESENTAR UMA ANÁLISE DO CHAMADO PRINCÍPIO DE UNIVERSALIZAÇÃO COMO APARECE NAS OBRAS DE JOHN RAWLS E JÜRgen Habermas. O UNIVERSAL É UM CONCEITO MUITO CARO A QUASE TODAS AS SOCIEDADES NA MEDIDA EM QUE SIGNIFICA UMA PREVALÊNCIA DO INTERESSE GERAL SOBRE O PARTICULAR. O UNIVERSAL SE MANIFESTA QUANDO CLASSES MENOS PRIVILEGIADAS PASSAM A TER ACESSO A ALGUMAS CONDIC̄õES DE VIDA DAS CLASSES MAIS ALTAS. ESSA ASCENSÃO, NO ENTANTO, PODE TER UMA CONTRAPARTIDA NEGATIVA: AS ELITES INTELECTUAIS APRESENTAM AS NORMAS QUE DEVEM VIGORAR NOS NOVOS TEMPOS ATRAVÉS DE UM DISCURSO ABSTRATO, IMPEDINDO QUE AQUELES QUE NÃO TÊM ACESSO A ESSE CAPITAL SIMBÓLICO SE BENEFICIEM DAS NOVAS CIRCUNSTÂNCIAS. ESTE aRTigo tentaRÁ MOSTRAR QUE AS OBRAS DE RAWLS E HABERMAS PODEM SER CARACTERIZADAS POR TAL FORMA DE UNIVERSALIZAÇÃO ABSTRATA.

\section{PALAVRAS-CHAVE}

Universalização CONCRETA E abstrata, Elites intelectuais, Capital simbólico, Skole

\section{ABSTRACT}

THE AIM OF THIS PAPER IS TO PRESENT AN ANALYSIS OF THE SO CALLED PRINCIPLE OF THE UNIVERSALIZATION AS IT APPEARS IN THE WORKS OF JOHN RAWLS AND JÜRGEN HABERMAS. THE UNIVERSAL IS A REVERED CONCEPT IN ALMOST ALL SOCIETIES AS FAR AS IT MEANS A PREVALENCE OF THE GENERAL INTERESTS OVER THE PARTICULAR ONES. IT PREVAILS UNDER CERTAIN HISTORICAL CONDITIONS WHEN THE LESS PRIVILEGED CLASSES HAVE ACCESS TO SOME OF THE PATTERNS OF LIFE OF THE UPPER CLASSES. THIS ASCENT HOWEVER HAS A NEGATIVE COUNTERPART: THE INTELLECTUAL ELITES PRESENT THE NORMS THAT MUST RULE THROUGH AN ABSTRACT DISCOURSE PREVENTING THOSE THAT DO NOT HAVE ACCESS TO THIS FORM OF SYMBOLIC CAPITAL TO BENEFIT FROM THE NEW CIRCUMSTANCES. THIS WORK WILL TRY TO SHOW THAT THE WORKS OF RAWLS AND HABERMAS MAY BE CHARACTERIZED AS THIS FORM OF ABSTRACT UNIVERSALIZATION.

\section{KEYWORDS}

ABSTRACT AND CONCRETE UNIVERSALIZATION, INTELLECTUAL ELITES, SYMBOLIC CAPITAL, SKOLE

\section{INTRODUÇÃO}

A procura de padrões universais de comportamento pode ser identificada em vários tipos de sociedades; em algumas essa procura é mais consciente que em outras, como no caso das sociedades ocidentais modernas, porém, mesmo em sociedades nas quais não há uma consciência muito clara desse fato essa busca existe, como será considerado adiante. Este artigo está interessado nas sociedades modernas e, de maneira específica, como essa preocupação aparece nos trabalhos de John Rawls e Jurgen Habermas, os 
autores que mais influenciaram a filosofia política e moral atuais. Assim, se propõe aqui, ainda que de modo geral, discutir o porque dessa procura pela universalização, para em seguida mostrar como ela se apresenta nas obras daqueles autores as suas implicações e seus aspectos críticos.

\section{A UNIVERSALIZAÇÃO E SUAS IMPLICAÇÕES}

Inicialmente se procurará mostrar quais os "lucros da universalização". Para tanto vai-se seguir de maneira bastante próxima a análise de Pierre Bourdieu (1994, 1997). Segundo ele, existe um reconhecimento universal do "reconhecimento do universal”, ou seja, "é um universal das práticas sociais reconhecer como válidos os comportamentos que têm como princípio a submissão, mesmo que hipócrita ao universal” (Bourdieu, 1994). Esse autor cita como um exemplo antropológico uma regra de organização familiar dos Kabila segundo a qual alguém do sexo masculino deve se casar com a prima patrilinear, apesar dessa forma de ligação caracterizar apenas de 3\% a 6\% dos casamentos nos grupos mais rigorosos. No entanto, todos aqueles que se casam, segundo essa regra, mesmo quando não o fazem com convicção, mas por outro tipo de interesse, procuram usar o fato como argumento para conseguir vantagens (lucros do universal) dentro dessa sociedade. Bourdieu aproxima esse comportamento com o objeto da crítica marxista à ideologia, isto é, como uma forma de universalização do interesse particular.

De outro lado, observa que as "estratégias de universalização que abrangem, em princípio, todas as normas e todas as formalidades oficiais, com tudo aquilo que possam ter de mistificação, repousam sobre a existência universal dos lucros da universalização. Estes são os determinantes de que o universal tenha chances não nulas de se realizar [...] a gênese desse tipo de comportamento não é concebível se não se identificar esse motor, que é o reconhecimento universal do 'universal', em outras palavras, o reconhecimento oficial da primazia do grupo e de seus interesses sobre o individuo e seus interesses" (Bourdieu, 1994).

Tais formas de conduta, as quais as classes dominantes geralmente elegem como paradigmas e nas quais celebram a cultura desinteressada, o puro, a moral kantiana, a contemplação do belo, etc., não podem preencher sua função simbólica de legitimação senão por que elas, precisamente, se beneficiam do princípio de um reconhecimento do universal. Referindo-se à situação histórica da burocracia moderna, seja de direita ou de esquerda, Bourdieu observa "que os grupos sociais que constituíram a burocracia prussiana ou a burocracia francesa, tinham interesse no universal, e por isso tiveram de inventar o universal (o direito, a ideia de serviço público, a ideia do interesse geral, etc.), ou seja, a dominação em nome do universal, para ter acesso a dominação" (Bourdieu, 1994).

De outro lado, a justificação do universal não seria possível sem que houvesse uma prática acadêmica capaz de produzi-la, e que pode ser identificada pela expressão 
scholastic view. Trata-se de um ponto de vista relativo ao mundo social, à linguagem e a outros objetos do pensamento, que se torna possível pelo ponto de vista da skole (lazer) - de onde vem à palavra escola - em sua forma particular de lazer intelectual. A adoção desse ponto de vista dá o direito de entrada exigido tacitamente por todos os campos do saber, a disposição "neutralizante" que implica a colocação em suspenso de toda a existência, de toda a intenção prática. A característica dessa atitude é deixar impensados os pressupostos de seu pensamento as próprias condições sociais que permitem a um grupo dedicar-se ao ponto de vista da skole e as disposições inconscientes de teses inconscientes, adquiridas através da scholastic view, muitas vezes inscritas no prolongamento de experiências originárias de distanciamento em relação ao mundo e às urgências da necessidade.

A implicação geral da fuga do mundo é destruir o objeto inicial de uma investigação e substituí-lo por puros artefatos e os aplicar sem reflexão à prática; a colocar na cabeça dos agentes sua própria visão escolástica e imputar a seu objeto, o que pertence à sua maneira de aprender ou a seu modo de conhecimento. Neste contexto, pode-se fazer uma crítica ao universal da skole: quando as práticas acadêmicas, pelo interesse de serem detentoras do saber, esquecem de considerar as condições históricas que instituíram certos comportamentos que passam a ser analisados por suas categorias de apreensão do mundo como definitivos e eternos, excluindo como irracionais outras práticas e outras formas de conhecimento.

Um caso paradigmático dessa situação de universalização abstrata ocorre com a chamada "ciência econômica"; e aqui vai se valer de novo de Bourdieu. Esse autor, em suas pesquisas antropológicas na Argélia, pôde estabelecer empiricamente que aquém de um certo nível de bem-estar econômico, assegurado pela estabilidade no emprego e pela posse de um mínimo de rendimentos regulares, os agentes econômicos não podem assegurar um mínimo de controle sobre o presente, não conseguem conceber nem realizar a maior parte das ações que implicam um esforço para controlar seu futuro, como a gestão racional de seus recursos ao longo do tempo, a poupança, o recurso ponderado ao crédito ou ao controle da fertilidade. Em outras palavras, há condições econômicas que permitem o acesso ao comportamento racional. Ora, essas condições não decorrem deste comportamento, mas são anteriores a ele. No entanto a ciência econômica, na medida em que desconhece esses condicionantes, afirma que as condições para obter bem-estar são a aplicação das suas próprias categorias que tomam como racionais e universais, tratando como um dom universal da natureza a disposição prospectiva e calculadora em relação ao mundo e ao tempo.

Além disso, a ocultação das condições que permitiram o aparecimento de comportamentos considerados favoráveis à humanidade impede que se determine se essas condições ainda existem - e se não existem quais modificações seriam necessárias para criar novos processos de racionalidade? A universalização abstrata, neste 
caso, ao não permitir a identificação dessas modificações, impede que novos grupos sociais acedam aos benefícios de uma universalização concreta.

De outro lado, a crítica ao universalismo abstrato que passa em silêncio as condições de acesso ao universal não deve levar à adoção de um relativismo cínico ou ao conformismo. O repúdio às formas de acesso ao universal por parte daqueles que se encontram excluídos, bem como o repúdio dos valores da verdade e dos valores efetivamente universais da emancipação, em nome de uma forma elementar de relativismo, contribuem para reforçar, de uma forma mais perigosa, ainda, a hegemonia existente e, geralmente, fazem transparecer uma espécie de falso radicalismo que tende a deixar as coisas como elas estão.

O objetivo dessas considerações preliminares é mostrar posteriormente de que maneira as obras de Rawls e Habermas incorporam essa forma de universalismo abstrato ao proporem uma oposição ao relativismo. A grande repercussão de suas obras no discurso ético, político e jurídico tornam essa reflexão ainda mais necessária.

\section{A VOLTA À FILOSOFIA POLÍTICA COM HABERMAS E RAWLS}

As obras recentes de Rawls e Habermas têm o mérito de reintroduzirem na discussão política conceitos como moralidade, justiça e legitimidade, como valores básicos da vida em sociedade e não como simples variáveis operacionais, como acontece na filosofia política de inspiração anglo-saxônica, que impõe como condição de uma análise política "científica" que esta seja value free.

Habermas referindo-se aos conceitos do direito formal o contrapõe a essa visão moderna ao afirmar que tais conceitos "oferecem a possibilidade de um procedimento construtivo e uma projeção normativa da ordem pública, concebida como um mecanismo racional, o que uma ciência política de orientação empírica abandonou radicalmente. Ao contrário do normativismo jusnaturalista (e mesmo do direito burguês), esta exclui de suas considerações científicas as questões morais/práticas da legitimidade ou, então, as concebe como questões empíricas o que tratam de descrever como uma crença na legitimidade” (Habermas, 1987). Em outras palavras, interpretam as questões de legitimidade como uma forma de aceitação da ordem social, independentemente de seu conteúdo valorativo, como na interpretação sociológica de Luhman, que reduz o princípio da legitimidade "a expectativas cognitivas que, no caso de uma decepção, não estaremos prontos a corrigir” (Habermas, 1997).

Os trabalhos de Habermas e Rawls, ao trazerem de volta as condições valorativas de justificação da realidade social, tiveram grande aceitação, especialmente, porque os autores partiram do conceito da moralidade kantiana, baseado na ideia de autonomia individual, cara ao pensamento liberal, dando à essa ideia uma interpretação procedimental e procurando enquadrá-la dentro de uma teoria que poderia ter uma extensão empírica. Essa concepção constitui uma alternativa à concepção hegeliana de que a 
constituição de uma comunidade livre somente seria possível mediante uma realidade que transcendesse os interesses de indivíduos atomizados.

Para justificar essa última observação, consideremos a crítica de Hegel à moralidade kantiana. Para Kant, uma decisão só seria moral se fosse independente de qualquer motivação externa ao indivíduo (prazer físico ou psicológico, busca de aprovação social, temor à lei, etc.); seria uma decisão a qual, quem a toma espera e deseja que os demais ajam sempre da mesma forma em relação a si mesmo. Daí a observação de Kant, que essa descrição estaria dentro do âmbito que identifica como moralidade (moralitat) apenas se essa decisão pudesse ser expressa como uma lei universal.

Kant formula essa ideia a partir do que chama "imperativo categórico":

A vontade absolutamente boa, cujo princípio tem que ser um imperativo categórico, indeterminada a respeito de todos os objetos, conterá, pois somente a forma do querer em geral, e isto como autonomia quer dizer: (1) a aptidão da máxima de toda a boa vontade, de se transformar a si mesma em lei universal, é a única que se impõe a si mesma a vontade de todo ser racional, sem subpor (2) qualquer impulso ou interesse como fundamento (Kant, 1960).

Hegel, embora considerasse a ideia desse imperativo como o primeiro passo para identificar a autonomia do ser humano, introduziu uma distinção que transcende essa regra que considera por demais formal e abstrata, quando se trata da sociabilidade humana. É a distinção entre a moralidade individual (moralitat), e a eticidade (sittlichkeit) que envolvem a totalidade da vida ética. A moralidade é limitada, pois regula apenas a relação de um indivíduo com outro,

... mas sobreposta a ela existe a vida mais ampla da comunidade, de pessoas relacionando-se com outras, não como indivíduos isolados, mas como indivíduos como membros de uma comunidade. Um dos argumentos mais fortes contra a ética kantiana é que o imperativo categórico não é operativo nas relações familiares, nas quais ele é superado pelo amor, de tal forma que o critério da moralidade (moralitat), pode também não ser válido para a vida política (Avineri, 1972).

No contexto da polis, portanto, o imperativo categórico não seria efetivo, como um princípio que permitisse a sociabilidade, quer dizer, a universalização dos interesses de agentes autônomos e livres, pois haveria a necessidade de um poder soberano, como em Hobbes, que realizaria a sociabilidade mediante a concessão por parte de cada indivíduo de sua autonomia: o relacionamento dos indivíduos entre si 
não decorreria do exercício de suas liberdades, mas de ele abrirem mão de parte delas para que a convivência fosse possível. Como observou Hegel:

A definição kantiana [...] em que o elemento essencial é a limitação da minha liberdade (ou de meu livre arbítrio), para que se possa estar de acordo com o livre arbítrio de cada um segundo uma lei geral, apenas constitui uma determinação negativa [...] uma vez aceito tal princípio, o racional só pode aparecer para essa liberdade, como uma limitação, não como razão imanente, mas sim como uma forma universal exterior (Hegel, 1976).

Para Hegel "a vontade racional humana, encontra um conteúdo, não cada um despojando-se de sua particularidade para alcançar sua liberdade e a universalidade [...] mas encontrando seus nexos com uma razão universal, chegando a discernir que aspectos de nossas vidas como seres particulares refletem verdadeiramente o universal concreto que é a razão (Geist)" (Taylor, 1983).

Ora, o que Habermas e Rawls pretendem fazer é, respondendo à crítica hegeliana sobre a visão liberal kantiana de liberdade, reformar essa visão e justificá-la a partir do pressuposto de que os indivíduos agindo isoladamente com base em sua razão (não em uma razão superior que consideram metafísica), possam realizar individualmente sua liberdade e ao mesmo tempo constituir concretamente o universal (a sociabilidade). ${ }^{1}$

\section{AS VISÕES DE RAWLS E HABERMAS}

Para Rawls (1971) a legitimação democrática do poder deve partir do conceito de 1iberdade individual ou liberdade negativa na acepção de Kant, e da determinação das condições em que as ações individuais compatíveis com esse conceito de liberdade seriam, também, compatíveis com uma moralidade social. Em sua análise Rawls procura apresentar a possibilidade de compatibilizar ambas as realidades, podendo incluir entre as liberdades negativas a propriedade. A restrição relativa à propriedade, contudo, tem relação com uma norma que Rawls chama de "princípio da diferença", de forma que o aumento da desigualdade, em termos de propriedade, e renda só poderá ser permitida caso tenha como subproduto a melhoria das condições de vida dos grupos menos privilegiados. Dessa maneira é possível ter-se um sistema econômico descentralizado compatível com o dinamismo de mercado, com a diferença que o critério de acumulação da riqueza, embora seja condicionado, em última análise, é determinada pela lógica do mercado.

Para desenvolver sua teoria, Rawls propôs uma interpretação do caráter humano que espera que todos aceitem como razoável, isto é, que todo o indivíduo tem certas metas que só poderão ser atingidas se este dispuser do que o autor denomina bens 
primários, os quais, inicialmente, supõe-se, se constituam de direitos e liberdades, poder e oportunidades, renda e riqueza (Rawls, 1971). O acesso a esses bens será facilitado pela associação entre os indivíduos, a qual, no entanto, só se justificará moralmente se tiver como consequência ganhos mútuos e nenhuma perda. A sociedade, portanto, seria a forma pela qual os indivíduos escapariam de uma situação que lhes impedisse realizar suas metas.

Ocorre, no entanto, que nessa associação haverá mais de uma alternativa possível de organização, de tal forma que surge a necessidade de se escolher uma delas. Essa escolha, segundo Rawls, implica a definição de uma série de princípios capazes de permitir a escolha da estrutura de distribuição baseada em princípios de justiça que "atribuiriam direitos e deveres para os membros da sociedade e a distribuição dos ônus e benefícios da cooperação social”. Ora, a definição dos princípios depende do que os indivíduos consideram a forma de sua autorrealização. Para Rawls, ao contrário do que pensam os utilitaristas benthamianos, o sentido de autorrealização é algo mais que o simples sentimento de sucesso e competência. A autoestima individual deriva, também, do sentimento de que suas ações foram honradas, de que suas realizações se justificaram diante dos outros. Assim a maioria das pessoas não quer parecer que venceu, quebrando certas normas e regras, nem tampouco que foram beneficiárias de normas injustas de discriminação ou de vantagens políticas. Na verdade, mesmo quando isso acontece, as pessoas procuram esconder o fato ou se justificar diante das outras, o que não deixa de ser uma situação em que a hipocrisia faz um aceno à virtude.

Diante dessa realidade, que princípios seriam escolhidos? A partir do que Rawls entende por uma concepção política de vantagens mútuas seria descartada toda a distribuição de ônus e benefícios que deixasse cada membro da sociedade em uma situação menos livre do que se permanecesse sozinho. A condição para isto acontecer seria dada pelo princípio da liberdade negativa: "Cada pessoa deve ter um direito igual à maior liberdade possível compatível com uma liberdade similar a dos demais", do que decorreria "que o esquema de cooperação social deve ser estável, deve estar de acordo com regras básicas aceitas voluntariamente” (Rawls, 1971) e, portanto, equitativas.

O segundo princípio, consistente com uma aceitação voluntária dos termos de associação, teria relação com a compatibilização da igualdade e da eficiência, partindo-se da hipótese, confirmada pelo fracasso das tentativas engenharia social, de que o igualitarismo seria autodestrutivo, até mesmo irrealizável. Seria, no entanto, necessário uma justificativa de cada passo que fizesse a sociedade se distanciar de uma distribuição igualitária. Para Rawls cada incentivo individual capaz de aumentar a desigualdade só seria justificado se melhorasse a posição absoluta de todos. Daí o "princípio da diferença, segundo o qual as desigualdades sociais e econômicas só poderão ser constituídas se forem: (1) "razoáveis de se esperar que, venham 
beneficiar a todos; (2) e sejam ligadas a posições sociais e profissões abertas para todos" (Rawls, 1971).

Do ponto de vista individual, esse raciocínio requer um critério de imparcialidade que se manifestaria por um princípio que deveria reger a elaboração de todas as normas: cada pessoa, ao decidir sobre sua ação, deveria estar certa de que, colocando-se na posição das demais, as consequências dessa ação não lhes seriam prejudiciais ou indesejáveis.

Esse comportamento ético equivaleria, em termos estratégicos, ao comportamento de pessoas que escolheriam uma distribuição dos bens produzidos em uma sociedade em uma situação de "ignorância" da posição que ocupam ou vão ocupar nessa sociedade, ou seja, diante da incerteza a respeito da sua posição, e admitindo a possibilidade de sua posição futura corresponder a dos menos privilegiados, os agentes procurariam uma forma de distribuição que tornasse melhor possível a posição deles mesmos.

Essa visão, no entanto, foi objeto de sérias contestações dos filósofos comunitaristas, especialmente Michael Sandel (1984); segundo ele, o contrato estabelecido a partir dos dois princípios mencionados seria, apenas, uma extensão da teoria da decisão, na qual seres humanos isolados e totalmente autônomos escolhem seus objetivos com base em um cálculo estratégico de seus respectivos interesses. Como observa Axel Honneth (1995), "supõe-se que o sujeito possua sempre a distância suficiente de todas as orientações de valor, capaz de permitir-lhe decidir, livre de qualquer constrangimento, como se tomasse a decisão de comprar alguma coisa". Supõe-se alguém que não esteja situado em nenhum contexto e em certa medida neutro em termos de valores.

Opondo-se a essa ideia, Sandel propõe que as pessoas não podem ser descritas de uma maneira adequada se não se levar em consideração seus objetivos de vida e orientações que os determinam. Esse autor argumenta ainda que toda a pessoa que já foi moldada por alguma forma de vida ou outra, em princípio, não pode estar na situação pressuposta por Rawls, no ato de decisão, isto é que possa adotar uma atitude indiferente diante de todos os projetos de vida possíveis” (Idem. p.235)

Diante dessas observações, Rawls procurou contextualizar a visão da "teoria da justiça "como equidade: uma teoria política e não metafísica" que "a teoria da justiça como equidade tem suas bases em uma intuição que nós julgamos estar implícita na cultura pública de uma sociedade democrática". Mais adiante, ele acrescenta "em oposição ao liberalismo como doutrina moral completa, a teoria da justiça como equidade procura apresentar uma concepção da justiça política que esteja inscrita nas ideias intuitivas de base da cultura pública de uma democracia [...] Assim a teoria da justiça como equidade procura precisar o centro de um overlaping consensus, isto é, as ideias intuitivas comuns que coordenadas em uma concepção política da justiça se revelarão suficientes para garantir um sistema constitucional justo” (Rawls, 1988). 
A favor de Rawls, e em oposição à crítica dos comunitaristas, pode-se verificar que a contextualização se constitui apenas em acentuar o que já estava explícito na teoria da justiça, ou seja, supõe-se que os participantes têm algo em comum, o que não significa que eles sejam necessariamente iguais.

Daí o comentário de Rawls de que pode haver, de fato, consideráveis diferenças entre os cidadãos a respeito das concepções de justiça, desde que tais concepções levem a julgamentos políticos similares. E isso será possível desde que diferentes premissas possam levar à mesma conclusão. Neste caso pode haver o que posso me referir como um "consenso parcial” (overlaping consensus) em vez de um consenso estrito [...] Naturalmente essa coincidência não precisa ser perfeita: será suficiente que uma condição de reciprocidade seja satisfeita. Ambos os lados devem acreditar que, embora suas concepções de justiça difiram, suas visões apoiam o mesmo julgamento de uma determinada situação e que continuarão as mesmas desde que suas posições sejam trocadas (Rawls, 1988).

$\mathrm{Na}$ verdade, Rawls não abandona sua concepção inicial de um contrato entre agentes livres e independentes, ele apenas evoca um contexto histórico (uma sociedade democrática, nos padrões da cultura ocidental), para reforçar a base de sua teoria em uma ética kantiana, que procura dar uma interpretação processual. Daí sua afirmação de que os princípios reguladores de uma sociedade justa seriam aqueles escolhidos com base em uma cultura pública de uma sociedade democrática, e que nos capacitassem a explicar o sentido pelo qual agindo a partir de tais princípios, expressariam as nossa natureza enquanto pessoas racionais livres. "Desde que todos são racionais e livres, cada qual deve ter um parecer igual ao adotar esses princípios, a menos que os princípios dos canalhas sejam adotados, quando então não será possível uma escolha livre para todos" (Rawls, 1971).

Considerando-se agora a visão de Habermas, podemos identificar um ponto de coincidência com Rawls, qual seja a importância que ambos atribuem ao processo de legitimação para a compreensão dos processos políticos, ou seja, esse processo deve envolver sempre considerações morais e práticas, o que uma ciência política de “orientação empírica" abandonou totalmente. Habermas, no entanto, distancia-se de Rawls ao considerar que a constituição de uma universalidade ética requer que esse processo seja desligado de uma conceituação monológica, que marcou a tradição formalista que vai de Kant ao próprio Rawls. Para Habermas, o ponto de vista adequado para a realização de um processo de legitimação normativa é fundamentalmente dialógico; é apenas através da estrutura comunicativa de um processo discursivo, envolvendo todos os afetados pelas normas propostas, que o processo de troca de papéis (reciprocidade), em que uns se colocam no lugar do outro, pode ser efetivamente realizado.

Assim, o foco da análise de Habermas vai se encontrar na possibilidade da universalização de interesses que deve nascer sempre em um contexto discursivo. Para esse autor 
O interesse é comum porque o consenso livre de constrangimento permite a realização apenas daquilo que todos podem querer (e) está livre de qualquer decepção, pois a interpretação das necessidades pelas quais cada indivíduo deve ser capaz de reconhecer aquilo que deseja se torna objeto de uma formação de vontade discursiva (Habermas, 1975).

Em artigo posterior Habermas (1990), procura detalhar mais seu ponto de vista, ao mostrar que a justificação discursiva das normas pressupõe não apenas as necessidades individuais, incluindo aqui um conjunto de bens específicos e o respeito ao indivíduo tomado isoladamente, mas também o respeito à sua forma de vida social e, portanto, o que está em jogo não é apenas a justiça, mas a solidariedade, pois

a justiça, concebida deontológicamente, requer a solidariedade como seu reverso. Não é uma questão apenas de dois momentos que se complementam como aspectos de uma mesma coisa [...] a justiça diz respeito à liberdade e direitos de um indivíduo único e autossuficiente, enquanto a solidariedade diz respeito ao bem-estar de seus semelhantes, e daqueles que a ele estão ligados intersubjetivamente em um a forma de vida comum e assim também à manutenção da integridade desta forma de vida. As normas morais não podem proteger os direitos iguais e as liberdades individuais sem proteger o bemestar de seus semelhantes e a comunidade à qual o indivíduo pertence (Habermas, 1990).

Implícita em tais observações encontra-se a ideia de uma sociedade cuja integração depende da possibilidade de os interlocutores encontrarem-se em uma posição de igualdade e livres de interesses externos como dominação, paixão, escassez, etc. Portanto, uma sociedade emancipada. Essa situação, dadas as condições históricas concretas, representa apenas uma hipótese contrafactual "pois apenas em uma sociedade que tivesse realizado a libertação de seus cidadãos, seria possível a comunicação no nível de um diálogo livre de todos com todos”. Ao mesmo tempo a possibilidade da emancipação encontra-se na possibilidade desse diálogo, mas isso "só pode acontecer quando "a filosofia descobre no curso dialético da História o conjunto das forças que impedem os esforços constantemente renovados de diálogo e os conduz para fora de uma comunicação livre, e [então] avança o processo cujo atraso retarda o progresso da espécie humana para sua emancipação" (Habermas, citado em Bubner 1981).

Habermas procura se aproximar de Kant ao mostrar que o princípio da discussão livre tem como corolário a construção de um contexto intersubjetivo de discurso, do qual decorre "que a validade da norma deve satisfazer à condição segundo a qual as consequências e os efeitos secundários do fato de que a normas que foram universalmente 
observadas, com a intenção de responder aos interesses de todos, podem ser aceitas sem limitações por todas as pessoas envolvidas" (Habermas, 1986).

Assim, Habermas propõe a reconstrução da ideia da razão prática de Kant em termos de uma razão comunicativa que tem como garantia o próprio caráter pragmático do discurso. A partir do momento em que as pessoas se dispõem a participar de um discurso, cada uma delas está admitindo a racionalidade dos demais, neste ponto Habermas segue Apel, que observou que "quem argumenta seriamente já admitiu necessariamente o ponto de vista da razão, isto é, ao ingressar no terreno do discurso argumentativo, se impugnar a validade universal das regras do discurso, incorrerá em uma contradição entre a proposição afirmada e a utilização performativa da validade das regras do discurso, pelo simples fato de argumentar" (Apel, 1990).

Em um primeiro momento, esse, é o ponto crucial da metodologia de Habermas, pois para ele o caráter pragmático do discurso torna possível a formação de uma vontade consciente na qual os interesses de cada indivíduo podem ser considerados sem que se destruam os laços sociais que ligam cada indivíduo com seu semelhante. Nesse sentido, o modelo de reciprocidade (role taking) utilizado no discurso não é equivalente ao do contrato social. Uma ética simplesmente processual ( $a$ la Rawls) torna-se parcial na medida em que a ideia de um acordo entre pessoas isoladas não é substituída pela ideia de uma formação de vontade racional, ocorrendo no "mundo da vida de indivíduos socializados".

No entanto, Habermas, em seus trabalhos mais recentes, especialmente Direito e democracia distância-se mais de Rawls ao se propor uma nova tarefa: utilizar a "teoria da discussão", para combater o positivismo jurídico, relacionando o direito com a justiça e a moral. Para Habernas, "o ponto de vista imparcial só pode tomar corpo no processo de uma argumentação intersubjetiva que obriga os participantes, por via de uma idealização, a estender os limites de suas perspectivas de interpretação" (Habermas, 1997).

Para tanto, esse autor terá de tornar explícito um princípio de organização social capaz de abrigar o princípio da discussão; e ele o faz recorrendo à existência do direito positivo. Assim esse princípio "não pode ir buscar sua legitimidade em um direito moral superior, mas em um processo supostamente judicioso de formação de opinião e vontade", de tal forma que o princípio moral não coincida obrigatoriamente com o princípio da discussão, como admitia a partir de sua herança de Apel. Para ele, agora,

é necessário situar o princípio da discussão em um nível de abstração ainda neutro em relação à distinção entre moral e direito, porque vai desdobrar-se em dois aspectos: em um princípio moral e em um princípio democrático. Neste caso é necessário mostrar-se em que medida o princípio da discussão está longe de esgotar o princípio da universalização, pois senão o princípio 
moral, simplesmente dissimulado, seria como no direito natural - uma única forma de legitimação do direito (Apel, 1990).

Habermas chama atenção para a importância de normas jurídicas como garantia contínua de liberdade para os agentes exporem seus pontos de vista. Daí observar que estes

como sujeitos de direito têm necessidade de ancorar a prática da autolegislação no contexto próprio do direito: é necessário que institucionalizem, em termos de normas jurídicas, os pressupostos comunicacionais e os procedimentos mesmos de um processo de formação de opinião e de vontade políticas, no qual o processo de discussão está aplicado. Em consequência o código jurídico estabelecido por meio do direito geral de dispor das liberdades subjetivas, deve ser complementado pelo direito de participação que garante com chances iguais o uso público da liberdade de comunicação. É dessa maneira que o princípio da discussão toma a forma jurídica de um princípio democrático (Ibidem, p. 488-489).

Tal condição não ocorre na argumentação de Rawls; para este o princípio que deve reger a constituição de um direito processual é independente da normatividade, mas depende profundamente da cultura e da tradição. Sobre esse ponto, observa

Em razão de sua hostilidade à ordem racional, Rawls não pode fornecer justificação para as perspectivas normativas da justiça; e embora ele não o reconheça, ele é em última análise um antinormativista, e é válido perguntarse se ele não cede também aí, ao contrário do que ele mesmo diz, a uma tentação sociologizante [...] o que é grave em tal procedimento é que confundiu o direito com o não direito, tornando-se o direito uma simples figura de fato: neste caso, uma ordem jurídica já não decorre de uma construção, mas torna-se no limite um simples dado (Goyard-Fabre, 2002).

À diferença de Rawls, pode-se encontrar em Habermas a formulação de uma teoria do direito positivo moderno. Este é ao mesmo tempo factual, legal ou institucionalizado e normativo, dotado de legitimidade, o que implica que seja aceito como obrigação e não por coerção. Sua legitimidade decorre de que é determinado por um processo discursivo no qual "os cidadãos estabelecem quais os direitos que devem ceder uns aos outros ao decidirem constituir-se em associação voluntária de societários jurídicos e ordenar sua vida de maneira legítima, graças ao direito positivo” (Habermas, 1999). Em Rawls essas condições não decorrem de um processo discursivo, mas são determinadas por um princípio moral de uma vez por todas. 
Do ponto de vista da filosofia prática, Habermas procura conciliar os elementos básicos da democracia liberal, o império da lei; alguém não é obrigado a fazer ou deixar de fazer, senão em virtude da lei; com o princípio da soberania popular, o princípio democrático, através da participação dos agentes na elaboração da lei; em outras palavras, compatibilizar Locke e Rousseau de modo que a distribuição das liberdades deva ser satisfeita por um processo democrático, que fundamenta a suposição de que o resultado da opinião pública e formação de vontade são razoáveis, o que mostra que as autonomias públicas e privadas pressupõem-se reciprocamente, sem a primazia de uma sobre a outra.

\section{A CRÍTICA DO UNIVERSALISMO DE RAWLS E HABERMAS}

As considerações acima podem questionar a possibilidade de se fazer uma crítica conjunta a Rawls e Habermas. Sem dúvida, é adequada a crítica de Habermas à limitação da visão de Rawls do contrato, não como algo capaz de constituir-se em um ato gerador da sociedade, como em Locke, Hobbes ou Rousseau, mas como pura ficção destinada a pensar uma sociedade imaginária regida, idealmente, pelos seus dois princípios de justiça.

Contrapondo-se a essa hipótese, Habermas procura mostrar a importância do princípio da discussão pelos elementos nele envolvidos. Porém, apesar de tal discordância, está implícita na análise desses autores a estratégia comum de construir uma forma de eticidade opondo-se à visão hegeliana do Geist - que não transcenda os resultados das práticas individuais.

Tanto para Habermas como para Rawls deve haver um processo de legitimação envolvendo todos os cidadãos. Embora esse processo difira para ambos, no estabelecimento de padrões éticos de convivência, os dois admitem que tais padrões não têm uma justificativa metafísica, mas se tornam necessários porque não há uma visão última que possa ser considerada determinante desses padrões. O falibismo humano admitido por eles vai exigir a tomada da palavra pelos cidadãos e a comunicação entre eles como eixo de uma convivência democrática.

Os dois autores admitem, ainda, que um processo público de justificação possa requerer um grande número e diversidade de razões, porém, a possibilidade de se chegar a um ponto de vista comum para Rawls depende de um consenso, embora parcial (overlaping consensus), sobre certos valores, enquanto para Habermas essa possibilidade não está dada por um modelo imaginário de contrato, mas pela razoabilidade que se manifesta através das condições ideais do discurso.

O ponto crucial comum, no entanto, que justifica uma avaliação de universalismo dos dois autores é que tanto Rawls como Habermas pressupõem que os agentes, apesar de terem algumas características individuais próprias, possuem características substanciais idênticas definidas abstratamente e as quais vão permitir o tratamento de 
seus problemas concretos. Para Habermas, a racionalidade que os membros da discussão devem admitir reciprocamente implica o surgimento de condições ideais do discurso que se concretizam pela elaboração de um direito racional. De outro lado, Rawls admite que um consenso universal pode ser obtido na medida em que este se fundamenta em ideias intuitivas que refletem ideais implícitos ou latentes na cultura pública de uma sociedade democrática, essas ideias se expressariam através dos "consensos parciais" ou overlaping consensus. Tais ideias, no entanto, nunca são atribuídas por Rawls a um estatuto concreto nem relacionadas a um tipo de comunidade política.

Em relação a ambas as hipóteses, pode-se considerar um problema levantado por Bourdieu cujas implicações serão consideradas adiante. A possibilidade de participação em um discurso ou em um processo de escolha dos princípios que vão reger uma sociedade justa depende de todos os agentes terem acesso a formas de racionalidade capazes de levar a um consenso livre não distorcido e aceito por todos, no caso de Habermas; ou por serem detentores, no caso de Rawls, de uma cultura liberal e democrática, que determina o overlapping consensus, ou seja, ambos supõem que os agentes detêm um capital simbólico que permite chegar a um acordo envolvendo todos os participantes. ${ }^{2}$

A partir dessa constatação nasce o problema concreto de se saber se essas hipóteses têm uma contrapartida concreta, se, na realidade, esse capital simbólico é possuído por todos os agentes. A desconsideração desse problema leva ao chamado ponto de vista que, parodiando Gilbert Ryle,

... conduz ao erro epistemológico mais grave em matéria de ciências do homem, que consiste em colocar o "sábio na máquina”, ${ }^{3}$ ou seja, ver todos os agentes sociais a partir da imagem do sábio [...] Ou mais exatamente, colocar os modelos que o sábio deve construir para justificar a existência de certas práticas, na consciência de todos os agentes (Bourdieu, 1994).

Ora, supor-se que todos os agentes atingiram esses padrões de racionalidade própria do sábio e, a partir dessa suposição irreal, justificar o processo de universalização e deixar de considerar outras formas de reivindicação por parte dos agentes que não se baseiam em tais padrões é cair, no que já foi identificado anteriormente, como o "ponto de vista escolástico".

A respeito, observa Axel Honneth, referindo-se basicamente a Habermas, o que pode também estender-se a Rawls:

Tal suposição leva a uma solução na qual os portadores empíricos de princípios morais socialmente inovadores são identificados a partir do nível ético, do ponto de vista de sua consciência moral e de suas ideias de justiça [...] Minha suposição é que Habermas [e eu acrescento Rawls] deve ignorar 
todas as potencialidades de ações morais que não podem ter alcançado um nível elaborado de julgamentos de valor, mas que estão incorporadas persistentemente em ações codificadas culturalmente de protesto coletivo ou mesmo de desaprovação moral silenciosa (Axel, 1995).

Axel Honneth expressa o fato de aqueles que não atingiram formas específicas de consciência moral, de caráter altamente abstrato, estarem excluídos da participação dos processos de discussão ou de assentimento dos padrões éticos mencionados. Nesse ponto, Honneth distingue as ideias de justiça formuladas na cultura dos experts burgueses e pela avant-garde política de um lado e a moralidade altamente situacional e fragmentária das classes excluídas de outro lado. Assim as ideias que acompanham e apoiam o protesto social das classes despossuídas podem ser entendidas como a mistura de dois sistemas generalizados de valor, como apontado por George Rudé:

O primeiro tipo dessas ideias é que o que eu chamo de elemento tradicional inerente a elas, baseado na experiência direta e na tradição oral e na memória do povo e não apreendida mediante a audiência de sermões ou discursos ou pela leitura de livros. Nessa fusão, o segundo elemento é o conjunto de ideias derivadas ou emprestadas de outros, muitas vezes tomando a forma de um sistema mais estruturado de ideias políticas ou religiosas como os direitos do homem, Soberania Popular, Laissez Faire e o Direito Sagrado da Propriedade, Nacionalismo, Socialismo ou as várias versões da justificação pela fé [...] Não há algo como uma tábula rasa, no lugar da mente onde novas ideias são moldadas, onde não havia nenhuma ideia anterior (Citado em Honneth, 1995).

Desse modo, é possível identificar duas formas de sistemas normativos: o sistema normativo que se desenvolve a partir dos estratos culturalmente qualificados que contêm ideias autoconsistentes e conectadas logicamente do certo e do errado e que estabelecem os princípios de uma ordem social justa, como observada por alguém exterior a essa experiência. Essa forma se opõe à ética social dos estratos mais baixos da sociedade, que configuram um complexo não coordenado de demandas reativas de justiça.

O segundo sistema de valores não se constitui em um sistema positivo de princípios de justiça, e pode ser identificado, segundo Barrington Moore, com o conceito de "consciência de injustiça”, que forma seu substrato cognitivo. Essas concepções não contêm a ideia de uma ordem moral total ou a projeção de uma sociedade justa abstraída de situações particulares, mas sim de uma alta sensibilidade a agressões e a reivindicações morais reconhecidas intuitivamente. "Essa moralidade interna representa 
apenas o lado negativo da ordem moral instituída; seu potencial inovador historicamente produtivo é o de apontar para possibilidades de injustiça como a força de uma crueldade histórica" (Honneth, 1995). Assim se considerarmos, por exemplo, as reivindicações do proletariado industrial, vamos verificar que elas se encontravam fundadas em sentimentos de injustiça e não eram formuladas claramente nem baseadas em objetivos eticamente referidos. A causa básica disso não é uma inferioridade cognitiva dos estratos sociais mais baixos, ela decorre de diferenças específicas de classe, determinadas por pressões normativas, ou seja, os horizontes de ação assim formulados estabelecem-se em diferentes níveis de generalidade por razões de caráter socioestrutural. A primeira razão para que isso aconteça é que as ocupações desempenhadas pelos grupos sociais subalternos não os condicionam a desenvolver um sistema de valores compatível com a participação nos processos de universalização vigente. Em sua rotina diária seus membros não sentem nenhuma pressão para participar, por exemplo, do overlapping consensus de Rawls ou, ainda, para desenvolver um sistema de despersonalização de interesses, como requerido por Habermas, para participar do diálogo e para a formulação de normas jurídicas. Assim, os membros desses grupos, em suas condições precárias de existência, não são considerados capazes de desenvolver códigos linguísticos e culturais para expressar suas reivindicações ou mesmo desenvolver certos comportamentos de racionalidade econômica.

Axel Honneth (1990) apresenta três argumentos para reforçar tais hipóteses:

a) Criou-se uma necessidade interna às classes superiores para justificar normativamente, para elas mesmas e para outros membros da sociedade, a ordem social existente da qual obtêm privilégios. O discurso da universalização abstrata é um testemunho dessa necessidade de racionalização.

b) O clima cultural não predispõe os extratos mais baixos da sociedade à qualquer pressão para que elaborem princípios normativos válidos para todos os seus integrantes. Aqueles que exercem o poder político econômico adquirem o monopólio para a aquisição de tal tradição cultural; eles possuem os meios simbólicos para decodificar suas próprias normas de ação em um sistema de valores que alcançam além de situações específicas.

c) Os meios culturais dos grupos dominantes concedem prêmios de reconhecimento social para as formulações mais abstratas e complexas de suas convicções normativas, especialmente quando tais diretrizes não indicam nenhuma diretriz de natureza prática, o que, como já foi visto identifica a atividade da skole. Em contraposição, os membros das classes inferiores não têm a mesma capacidade para refletir sobre suas normas de ação, mesmo porque estão excluídos de reprodução cultural incorporada no sistema. A prova disso é que quando procuram formular suas reivindicações, recorrem a clichês 
normativos, incapazes de identificar as verdadeiras causas de sua situação. Assim, "desde que nem suas premissas de valor, nem suas ideias de justiça são transparentes, a moralidade interna de sua consciência de injustiça social pode ser percebida, apenas indiretamente, na base de padrões caracterizados pela desaprovação moral dos eventos e processos sociais” (Honneth, 1995).

Em seguida, Honneth apresenta mecanismos de controle social que dificultam ou mesmo impedem a formação de conceitos positivos de justiça e igualdade por parte dos grupos subalternos. São de duas ordens: processos culturais de exclusão e processos institucionalizados de individuação. Os primeiros caracterizam as estratégias que limitam as possibilidades da experiência de injustiça mediante a desqualificação sistemática dos meios simbólicos, linguísticos, para sua expressão. Essas estratégias são utilizadas por agências de educação pública, pelos órgãos da indústria cultural e por fóruns de publicidade política. Os sistemas de linguagem utilizados e ensinados hoje pelas agências de socialização, e divulgados pela mídia, formalizam e despersonalizam experiências de injustiça específicas de grupos e classes, de forma que fiquem excluídos do mundo da comunicação. O processo de dessimbolização, estudado por autores como Oskar Negt e Alexandre Kluge, são também acompanhados pela repressão institucional de tradições culturais e dos processos de aprendizagem de movimentos de resistência social. Honneth apresenta como um caso concreto dessa situação a exclusão da arena pública na Alemanha Federal do testemunho histórico dos movimentos operários.

Os processos de individualização institucional são as estratégias estimuladas pelo estado ou por outras organizações que visam se opor ao perigo da comunicação relativa a experiências específicas de injustiça, mediante o estímulo a ações de orientação individualista. Assim, elas destroem a infraestrutura comunicativa que constitui a base de uma mobilização cooperativa e de uma elaboração dos sentimentos de injustiça. Essas estratégias são altamente complexas e vão desde o estímulo ao processo de ações individualistas envolvendo riscos à destruição de comunidades de vizinhanças capazes de formar consciência em grupo, e ao estabelecimento de mercados competitivos de trabalho dentro das empresas ou escritórios. A ideologia da autotrealização (achievement) é o complemento da tal estruturação. Além disso, a organização de agências de seguro privadas, em substituição às agências públicas, tem sido um obstáculo às formas de organizações coletivas e um estímulo à percepção individualizada de riscos (Honneth, 1995).

\section{CONCLUSÃO}

A crítica que se fez até agora à monopolização do universal por parte daqueles que tiram vantagens dessa monopolização, seja do ponto de vista econômico ou do ponto 
de vista da detenção do "capital simbólico", não implica negar que a busca por níveis mais elevados de universalização não tenha avançado, em termos de progresso da razão, e que na luta para se atingir níveis mais amplos de universalização não tenha havido apelos à razão e à verdade. Consideremos o processo de uma universalização, por exemplo, que levou à constituição do direito positivo. Segundo a observação de Antonio Gramsci, quando ele compara a universalização ocorrida na revolução francesa com a universalização decorrente da reforma religiosa protestante,

... apesar de a França ter sido dilacerada pelas guerras religiosas, obteve uma grande reforma popular no século XVIII com o iluminismo, o voltaireanismo, a Enciclopédia, que precedeu a revolução de 1789; tratou-se, na realidade, de uma grande reforma intelectual e moral do povo francês, mais completa do que a luterana alemã, já que envolveu também as grandes massas camponesas, pois teve um fundo laico acentuado ao tentar substituir a religião por uma ideologia completamente laica, representada pela vinculação nacional e patriótica. Tampouco ela, contudo, produziu um florescimento imediato da alta cultura, com exceção da ciência política na forma da ciência positiva do direito (Gramsci, 1978).

De outro lado, a criação do direito positivo não teria sido possível se não houvesse microcosmos sociais que, através de um trabalho de muitos séculos, formularam as bases intelectuais para justificar a existência da soberania do Estado. Assim, ao mesmo tempo em que através de um conjunto de conceitos procedimentos, e de formas de organização política destinados a servir ao interesse geral, os membros desses microcosmos puderam se apropriar das funções públicas como depositários dos poderes associados à instrução e ao mérito e não mais decorrentes dos privilégios do nascimento.

Apesar da democratização trazida por tais alterações, observa-se uma monopolização dos instrumentos de exercício do poder por grupos sociais específicos. Inicialmente nas mãos dos canonistas medievais, posteriormente pelos advogados e professores no século XIX, e pelos tecnocratas na idade contemporânea. Um processo de universalização efetivo pode estagnar quando os detentores do "capital simbólico" e grupos sociais interessados supõem que a realidade passa a ser identificada com suas categorias de apreensão e de manipulação dessa realidade.

Daí a possibilidade, em certos contextos, de as práticas de "universalização" passarem a ter princípios pouco universais: as racionalizações pela dissimulação dos lucros e interesses privados nelas envolvidos. Para se escapar dessa armadilha não há outra receita senão a que agora atinge o nível da ação política, pois "não se pode escapar do populismo ou do conservadorismo, duas formas de essencialismo tendentes a consagrar o statu quo, senão mediante o esforço de universalizar as condições de acesso ao universal” (Bourdieu, 1994). 
Essas alterações, no entanto, transcendem os procedimentos codificados nos padrões éticos vigentes ou as normas jurídicas formulados na sistematização de Rawls ou Habermas. Nestas, o político é substituído por uma ética racional que institui uma forma de eticidade que pressupõe sempre regras definidas a partir de hipóteses sobre a natureza humana, e um direito positivo que define as normas de convivência e organização social. De acordo com Habermas “os procedimentos democráticos não retiram sua força de legitimação, apenas, nem predominantemente, da participação política, mas antes do acesso ao processo deliberativo, cuja estrutura fundamenta uma expectativa de resultados racionalmente aceitáveis" (Habermas, 2001).

Aqui surge um problema: quem determina a linha de separação entre o que é aceitável e não aceitável, a que se pode chegar a partir de um processo discursivo como o proposto por Habermas? Ou entre o legítimo e o ilegítimo que possa ser determinado a partir de um acordo decorrente de um overlaping consensus? A situação do "consenso parcial" é muito ampla para se determinar o conteúdo específico de certas normas. Até que ponto se pode identificar nesses contextos os resultados que são aceitáveis, sem alterar os padrões éticos ou jurídicos vigentes? Não há uma fronteira clara entre essas decisões e as decisões determinadas pelo próprio conjunto de normas éticas ou jurídicas vigentes a partir de uma “ética racional”. Daí, poder se lembrar a crítica à repulsa liberal ao conceito de política, feita pelo grande jurista conservador, e em alguns momentos reacionário, Carl Schmitt:

Aquelas decisões vão depender de quem as interpreta, as define e as usa. Quem determina o que é a paz, o que é o desarmamento, quais os tipos de intervenção, o que são a ordem e a segurança pública. Uma das manifestações mais importantes da vida legal e espiritual da humanidade é o fato de que quem quer que tenha o poder verdadeiro pode determinar o conteúdo das palavras e dos conceitos. Caesar dominus et supra gramaticam [Cesar é o senhor das palavras e da gramática] (Schmitt, citado em Mouffe, 2005).

Da mesma forma que quem define o uso dos termos e a gramática realiza uma ação política, uma redefinição desses termos também tem de ter o efeito de uma ação pública, que se constitui colocar, em termos sociologicamente realistas, "a questão da moral em política ou da moralização da política", isto é "interrogar-se de maneira prática sobre quais condições deveriam ser colocadas para que as práticas se encontrem submetidas a um teste de universalidade, de modo que imponham aos agentes nelas engajados limites e controles que sejam levados a estratégias da universalização real”.

Certamente, esse esforço depende da aplicação de uma real politik capaz de enquadrar, instaurar ou reforçar padrões democráticos, mediante a criação de associações e movimentos, manifestações e manifestos, capazes de levar àquele objetivo. 
A análise desse processo, no entanto, requer um aprofundamento, que vai além dos objetivos deste artigo.

: ARTIGO APROVADO (10/07/2010) : RECEBIDO EM 05/01/2010

\section{NOTAS}

1 Para deixar mais clara a posição de Hegel é preciso lembrar que o autor não realiza uma negação absoluta da ideia de liberdade individual no sentido kantiano, mas propõe uma superação, pois considera importante como um primeiro momento da definição da liberdade objetiva, mas deve haver uma superação (aufhebung) dessa ideia. Nesse processo de superação, e nisso talvez Hegel seja menos metafísico que Habermas e Rawls, ele toma como base não qualquer sociedade e qualquer forma de razão natural, mas considera um processo educativo, que ocorre na "sociedade civil”. Para Hegel a sociedade civil é o espaço dinâmico no qual as trocas socioeconômicas e os conflitos resultantes são organizados por uma forma de razão, "superando" os conflitos.

2 “Capital simbólico" é um conceito usado por Bourdieu que significa, metaforicamente, a soma do reconhecimento cultural de prestígio que um indivíduo ou grupo social pode adquirir mediante uma manipulação hábil do sistema de símbolos sociais.

3 A imagem do sábio na máquina reporta-se a uma observação de Ryle segundo a qual alguém vendo uma máquina a vapor ou elétrica funcionar, e desconhecendo os princípios de funcionamento, explica o fato usando a ideia de que existe um fantasma ou um homúnculo na máquina.

\section{REFERÊNCIAS BIBLIOGRÁFICAS}

APEL, K. O. Una Ética de La Responsabilidade em La Era de La Ciência. Buenos Aires: Editorial Almagesto, 1990, p. $17,18,490$.

AVINERI, S. Hegel's Theory of Modern State. Cambridge: Cambridge University Press, 1972, p. 137.

BOURDIEU, P. Raisons Pratiques - Sur La Theorie de L'Action. Paris: Editions du Seuil, 1994, p. 165, 167, 222, 227. Meditations Pascaliennes. Paris: Editions du Seuil, 1997.

BUBNER, R. La Filosofia Alemana Contemporanea. Madri: Ediciones Catedra, 1984, p. 229.

GOYARD-FABRE, S. Os fundamentos da ordem jurídica. Tradução de Claudia Berliner. São Paulo: Martins Fontes, 2002, p. 244, 245.

GRAMSCI, A. Concepção Dialética Da História. Tradução de Carlos Nelson Coutinho. Rio de Janeiro: Civilização Brasileira, 1978, p. 105, 106.

HABERMAS, J. Legitimation Crises. Boston: Beacon Press, 1975, p.108. Morale et Communication. Paris: Editions du Cerf, 1986, p. 86, 87.

- Teoria de La Accion Comunicativa. Madrid: Taurus, 1987, p. 19s, 492.

. Ecrits Politiques. Paris: Edition du Cerf, 1990, p.47.

Debat sur la Justice Politique. Paris: Edition du Cerf, 1997.

The Post national constellation. Cambridge: Polity, 2001, p. 110.

. Droit et Democratie. Paris: Gallimard, 1997, p. 488.

HEGEL, G. W. F. Princípios da Filosofia do Direito. Lisboa: Ed. Livraria Martins Fontes, 1976, p. 44, 45. 
HONNETH, A. The Fragmented World of the Social. Nova York: State University of New York Press, 1995, p. 208, 209, 212-214.

KANT, E. Fundamentação da Metafísica dos Costumes. Tradução de Paulo Quintela. Lisboa: Atlântida, 1960, p. 91. MOUFFE, C. On the Political. Londres/Nova York: Routledge, 2005, p. 87.

RAWLS, J. A Theory of Justice. Cambridge: Harvard University Press, 1971, p. 6, 60, 62, 256, 257.

. La Theorie de la Justice comme Equité, une Theorie Politique et non pas Metaphisique. In: AUDARD, C. Individu et Theorie Sociale. Paris: Editions du Seuil, 1988, p. 288, 304, 381.

SANDEL, M. Liberalism and its Critics. Oxford: Basil Blockwell, 1984.

TAYLOR, Ch. Hegel y la Sociedad Moderna. México: Fondo de Cultura Economica, 1983, p. 157

Luiz Antonio de Oliveira Lima

Av. Nove de Julho, 2029 - $11^{\circ}$ andar Bela Vista - 01313-902

São Paulo - SP - Brasil luiz.limalafgr.br
DOUTOR EM CIÊNCIAS ECONÔMICAS PELA UNICAMP Mestre em Economia Pela Michigan State University Professor Titular da Fundação Getulio Vargas (FGV) 
